\title{
MULHERES NA POLÍTICA: UM ESTUDO NA CÂMARA MUNICIPAL DE UMA CIDADE DO SUL DE MINAS GERAIS
}

\author{
Jéssica de Martins Sampaio ${ }^{1}$ \\ Mariane Ferreira Pinto de Paula ${ }^{2}$ \\ Adílio Renê Almeida Miranda ${ }^{3}$
}

\begin{abstract}
Resumo: A representação das mulheres na política brasileira ainda é baixa se comparada a dos homens. Mesmo com a política de cotas nas candidaturas pelos partidos políticos, elas ainda não têm conseguido se eleger na mesma proporção em que se candidatam. Além disso, para aquelas que se elegem, há outros desafios advindos de desigualdades históricas vivenciadas por mulheres. Nesse sentido, este estudo tem como objetivo discutir a inserção e vivência de mulheres na política, no legislativo de uma cidade do sul de Minas Gerais, na perspectiva dos vereadores e vereadoras. O referencial teórico trata do significado de representação e participação feminina, bem como sobre a inserção das mulheres na política e a busca pela igualdade de gênero. A pesquisa é de natureza qualitativa. Para coleta de dados foram realizadas cinco entrevistas semiestruturadas com três vereadores, uma vereadora e uma ex-vereadora. A análise dos resultados foi feita por meio da análise de conteúdo. Os resultados mostram que os entrevistados não têm consciência quanto ao processo histórico e social de desigualdades vivenciado por mulheres e a importância da política de cotas, que visa minimizar essa questão.
\end{abstract}

Palavras-chave: Mulheres na política; participação política; legislativo.

\begin{abstract}
The representation of women in Brazilian politics is still low if compared to men. Even with quota policy in applications by political parties, women still have not been able to elect the same extent they apply to. Furthermore, for those who get elected, there are other challenges arising from historical inequalities experienced by women. Thereby, this paper aims to discuss the women insertion and experience in politics, in legislative power from southern Minas Gerais, in the aldermen' and councilwomen' perspectives. The theoretical framework is about the meaning of women's representation and participation, as well about the insertion of women in politics and the search for gender equality. The research is qualitative. For the data collection, five semi-structured interviews were made with three aldermen, one councilwoman and one ex-councilwoman. The results analysis was made by means of content analysis. The results show that the interviewed are unaware of the process of historical and social inequalities experienced by women and the importance of quotas policy, which aims to minimize this issue.
\end{abstract}

Keywords: Women in politics; politic participation; legislative.

Resumen: La representación de las mujeres en la política brasileña todavía es baja si comparada a la de los hombres. Aun con la política de cuotas en las candidaturas por los partidos políticos, ellas aún no han logrado elegirse en la misma proporción con que se presentan a la candidatura. Además, para aquellas que logran elegirse, hay otros desafíos advenidos de las desigualdades históricas vivenciadas por las mujeres. En ese sentido, ese estudio pretende discutir la inserción y vivencia de las mujeres en la política, en el poder legislativo de una ciudad del sur de Minas Gerais, desde el punto de vista de los concejales y de las concejales. El marco teórico trata del significado de la representación y participación femenina, así como sobre la inserción de las mujeres en la política y la busca por la igualdad de género. La naturaleza de la investigación es cualitativa. Para la recolección de datos fueron realizadas cinco encuestas semiestructuradas con tres concejales, una concejal y una ex concejal. El análisis de los resultados fue hecho por medio del análisis del contenido. Los resultados demuestran que los entrevistados no tienen consciencia del proceso histórico y social de desigualdades vivenciado por las mujeres y la importancia de la política de cuotas, que pretende minimizar esa cuestión. Palabras-clave: Mujeres en la política; participación política; legislativo.

\section{INTRODUÇÃO}

A diferença de direitos entre homens e mulheres sempre esteve presente nas sociedades antigas e modernas, onde a supremacia masculina era tida como normal e necessária para a manutenção de uma ordem social (KROOK, 2010). Mesmo com registros de mulheres que buscavam sua emancipação durante todo o desenvolvimento das sociedades, foi somente no final do século XIX que o movimento em busca da liberdade

\footnotetext{
${ }^{1}$ Mestranda em Gestão Pública e Sociedade pela Universidade Federal de Alfenas

${ }^{2}$ Graduada em Ciência e Economia pela Universidade Federal de Alfenas

${ }^{3}$ Doutor em Administração pela Universidade Federal de Lavras e professor adjunto na Universidade Federal de Alfenas
} 
e independência tomou força e consistência, principalmente na Europa, por meio da articulação de mulheres a fim de obter direitos políticos e representação (DIAS; SAMPAIO, 2011), articulação esta que se intensificou na década de 1960, quando mulheres foram às ruas, influenciadas por princípios do movimento feminista como a liberdade e igualdade de gênero (MACIEL, 2009).

No contexto brasileiro, a busca pela inserção e representação da mulher na política já datava do início do século XX, quando, em 1905, três mulheres nascidas em Minas Gerais conseguiram se candidatar e foram liberadas para votar nesse ano (BRASIL, 2012). Mais tarde, em 1918, o Partido Republicano Feminista foi criado por Leolinda Daltro objetivando a mobilização das mulheres na luta pelo reconhecimento político (COSTA, 2005). Em 1928, o direito ao voto foi conquistado por 20 mulheres no estado do Rio Grande do Norte (DIAS; SAMPAIO, 2011), o qual foi estendido para todas as mulheres do Brasil, em 1932 (BRASIL, 2012).

Décadas mais tarde, iniciativas do governo para inclusão de mulheres na política começaram a surgir, como, por exemplo, a política de cotas, sendo esta uma proposta apresentada incialmente por Marta Suplicy, contou com o apoio de 20 deputadas e foi introduzida na Câmara dos Deputados no ano de 1995 (RANGEL, 2010). Posteriormente, se tornou parte da Lei 9.504, de 1997, que, após reformulada no ano de 2009, estabelece que os partidos políticos devem preencher no mínimo 30\% e no máximo $70 \%$ das candidaturas de cada gênero (BRASIL, 1997). A criação de tal política afirmativa é uma forma de dar mais espaço às mulheres na política, visto que ainda há pouca atuação da mulher na política, consequência, por exemplo, do não reconhecimento do espaço público político como "pertencente" à mulher (LIMA, 2010). Sendo assim, a política de cotas pode auxiliar a inserção de mulheres na política, visto que torna obrigatória a presença das mesmas neste meio.

Em âmbito nacional, a participação de mulheres no legislativo não chega a ser metade da dos homens. Inclusive, nas eleições de 2014, a porcentagem de ocupação de mulheres nas cadeiras da Câmara dos Deputados e Senado foi de cerca de 10\% (PORTAL EBC, 2014). No município do sul de Minas Gerais, contexto desta pesquisa, não é diferente em relação às mulheres no âmbito do legislativo, mais especificamente na câmara de vereadores: no mandato atual (2012 - 2016), há apenas uma vereadora e a cidade nunca elegeu uma prefeita.

Nessa perspectiva, o objetivo deste trabalho é discutir a representação e a participação políticas e vivência de mulheres na câmara de uma cidade do sul de Minas Gerais, na perspectiva dos vereadores e das vereadoras. Para tanto, foi realizada uma pesquisa qualitativa. Os dados foram coletados por meio de entrevistas semiestruturadas com uma vereadora, uma ex-vereadora e três vereadores. A análise de dados se deu por meio da análise de conteúdo.

O trabalho é dividido em cinco sessões, sendo, a primeira, esta introdução. Em seguida, apresentase o referencial teórico que discute as cotas para mulheres na política e a busca pela igualdade entre homens e mulheres na política. Adiante, são apresentados os procedimentos metodológicos utilizados na pesquisa. A quarta sessão, resultados e discussões, trata da análise das entrevistas realizadas. Finalmente, são feitas as considerações finais.

\section{O SIGNIFICADO DA REPRESENTAÇÃO E PARTICIPAÇÃO FEMININA}

A construção de um significado para representação política permeia, principalmente, a noção da democracia representativa que se expandiu e alterou as características dos políticos de diversos níveis, os quais passaram a ser enxergados não como quem eles são, mas sim o que representam (PHILLIPS, 2001). Young (2006) coloca que esta representação é uma relação complexa entre espaço e tempo e é necessária visto que, 
na sociedade atual, os indivíduos são incapazes de estarem presentes em todos os órgãos, necessitando que alguém tome as decisões que influenciam nas suas vidas.

Para que a representação política ocorra de uma forma mais democrática, a pluralidade de atores é necessária (YOUNG, 2006) e a demanda para que a presença política de diferentes grupos aumente é crescente na sociedade contemporânea (PHILLIPS, 2001). Dentre esta demanda por maior representação, está a reivindicação por presença igualitária de diferentes grupos, como homens e mulheres (PHILLIPS, 2001). Esta abordagem está pautada em uma diferença recorrente entre homens e mulheres na sociedade e dentro do ambiente político, como ressaltam Migual e Biroli (2010), ao analisarem que a política ainda é enxergada como um espaço masculino, o que consequentemente propicia que os homens tenham maiores chances e mais proximidade com os ocupantes de cargos políticos que são homens, na maioria das vezes. Esta situação é contrária à noção, já citada, de representação mais democrática e adequada à política que tem como seio a participação em diversos âmbitos, dentre ele o legislativo, de diferentes grupos sociais no processo de tomara de decisão (PHILLIPS, 2001).

Outro fator que se torna necessário para a efetividade da representação é o relacionamento mais próximo entre o representante e os membros do seu eleitorado (YOUNG, 2006) e as características do indivíduo que representa este eleitorado. Apesar de haver algumas colocações de que dentro dos grupos sociais há outras diferenças específicas entre os próprios membros que um membro do grupo não conseguiria representar, é necessário refletir, como coloca Phillips (2001), que no caso das mulheres, uma mulher ocupando um cargo político tem a capacidade de reivindicar diversas demandas de diversas identidades dentro do grupo ao qual pertence. É inegável a individualidade apresentada pelas mulheres, porém existem pensamentos nas sociedades que atingem todas as mulheres, como a lógica de que o homem se encaixa melhor na política (SACCHET, 2011). Além disto, a presença de mulheres na política é precedida por um caminho de estereótipos, desproporcional carga de trabalho doméstico dificultando a existência de tempo para participar de atividades políticas, construção social da competência do espaço doméstico às mulheres, entre outros (MIGUEL; BIROLI, 2010).

Torna-se então necessário compreender que a representação e a participação feminina não são simplesmente mero atendimento às leis para um clima de estabilidade na política, mas sim reconhecer que a predominância de um grupo é maléfica para a sociedade de uma maneira geral (PHILLIPS, 2001), pois a representação da sociedade é melhor realizada quando existe a pluralidade de grupos dentro da política (YOUNG, 2006). Uma das formas de concretizar esta pluralidade, e também uma das preocupações contemporâneas acerca de uma representação mais justa, são as cotas (PHILLIPS, 2001) que, segundo Young (2006, p. 183), são meios “aceitáveis e desejáveis de promover a inclusão de perspectivas e interesses diversificados”, como no caso das mulheres.

De maneira mais específica, a questão acerca de cotas de gênero foi formalmente discutida na $1^{\mathrm{a}}$ Conferência Ministerial Europeia sobre a igualdade entre homens e mulheres, em 1986 (RANGEL, 2010), porém, no Brasil, tal discussão aconteceu somente quando o país adotou as medidas debatidas durante a IV Conferência Mundial sobre a Mulher que ocorreu em Beijing, em 1995. Como primeira experiência, foi estabelecida uma cota mínima de 20\% para a candidatura de mulheres nas eleições de 1996. Em 1997, para as eleições do ano seguinte, foi estabelecido através do $\S 3^{\circ}$ do artigo 10 da lei $n^{\circ}$ 9.504/1997 que os partidos políticos deveriam preencher no mínimo 30\% e no máximo 70\% das vagas para candidaturas de cada sexo (BRASIL, 1997). Além desta, a alteração do inciso V do artigo 44 da Lei 9.096/1995 feita pela Lei 12.034/2009 impôs que, no mínimo, 5\% dos recursos do Fundo Partidário fossem aplicados na criação e manutenção de programas que visassem a promoção e difusão da participação das mulheres na política (BRASIL, 2009). 
O sistema de cotas que vigora no Brasil é o de legislação nacional de reservas de vagas partidárias, citado anteriormente, porém, esse não é o único tipo de cotas para mulheres na política. Além dele, podem ser listados outros dois: as cotas como iniciativas dos partidos políticos e as cotas como reserva de assentos parlamentares (ARAÚJO, 2001).

O sistema de cotas como iniciativa dos partidos políticos, como o nome já sugere, é uma reserva de vagas para a candidatura de mulheres pelos partidos políticos. Ou seja, cada partido político pode reservar uma quantidade de vagas para a candidatura de mulheres. Neste caso, é uma iniciativa voluntária, não uma lei. Portanto, se houver partidos que não quiserem reservar essas vagas, eles não têm essa obrigação (ARAÚJO, 2001).

Por último, o sistema de cotas como reserva de assentos parlamentares. Nesse caso, a reserva de vagas é direcionada para a eleição de mulheres, ou seja, independente se os homens foram mais votados ou não, as mulheres seriam eleitas pela porcentagem estabelecida para elas nas cadeiras parlamentares, estando mais presente na Ásia, África e em países do Leste Europeu (PAXTON; HUGHES, 2016).

A necessidade das cotas ia além da eleição de mulheres, segundo as próprias mulheres que foram eleitas deputadas na época em que começou a ser implantada a política de cotas no Brasil (GROSSI; MIGUEL, 2001). As cotas também englobam a questão da representatividade dos interesses femininos, que acontece de maneira mais eficaz e eficiente quando feita pelas próprias mulheres do que quando pensada pelos homens (PAXTON; HUGHES, 2016), além de expandir o leque de interações com a sociedade.

Em termos gerais, a população preferia e, prefere até hoje, em vários lugares, eleger homens (GROSSI; MIGUEL, 2001), resultado de uma cultura e de uma sociedade que fragiliza a capacidade das mulheres de representarem a si mesmas (BRASIL, 2014).

\section{GÊNERO E POLÍTICA}

A manutenção de papéis para homens e mulheres nas diferentes sociedades não atendia, de maneira geral, a nenhuma lei específica, porém, sempre houve a ideia de que há lugares pré-definidos para os mesmos e tais lugares devem ser respeitados (ARAÚJO, 2011). É como um acordo não verbal entre homem e mulher: ela tem a função de ser mãe, ele tem a função de dar proteção à família e, com isso, acaba sendo o dominador da mulher, que a proíbe de participar da vida política (MIGUEL, 2001). Dias e Sampaio (2011) enfatizam que, no caso do Brasil colônia, mesmo não havendo nenhum tipo de proibição formal, a participação da mulher na política não acontecia por existir uma regra de conduta que não permitia que isso acontecesse. $\mathrm{O}$ motivo da pouca representação da mulher no meio político se dá pelos mesmos motivos que algumas mulheres ainda enfrentam discriminação no mercado de trabalho em algumas áreas de atuação, ou seja, o preconceito que provém de uma sociedade machista e patriarcal (ARAÚJO, 2001).

Apesar de haver distintas percepções sobre a posição da mulher na sociedade, o presente trabalho busca se orientar por uma visão que combate a ideia de dominação ou opressão feminina exercida pelos homens. Assim, argumenta-se que, apesar de as mulheres não poderem exercer plenamente seus direitos tanto na vida política, quanto na vida privada, as mesmas buscaram sempre se articular criando movimentos de luta que buscavam não somente direitos políticos, como também direitos sociais (DIAS; SAMPAIO, 2011)

As lutas pelos direitos das mulheres já se mostravam presentes no Brasil no início do século XX, com a criação do Partido Republicano Feminino (BRASIL, 2014) e com a Constituição de 1934 que assegurou o direito ao voto às mulheres (DIAS; SAMPAIO, 2011). Porém, foi na década de 1960 que ganharam força 
uma série de manifestações pelo mundo, em que as chamadas minorias, como mulheres e negros, buscaram reivindicar seus direitos iguais aos dos homens brancos (MACIEL, 2009), dando força à ideia de que o pessoal também era político, questionando os parâmetros políticos, sociais e culturais que estavam estabelecidos na sociedade (COSTA, 2005). Tal década ficou conhecida como a época em que "os cabelos cresceram e as saias encurtaram", ou seja, alguns homens começaram a ter cabelos compridos (e eram ridicularizados e associados a delinquentes) e algumas mulheres começaram a usar saias curtas e calças jeans (o que, para a época, era algo fora dos padrões e o que fez com que elas também fossem ridicularizadas) (MACIEL, 2009).

Os papéis sociais dos homens e mulheres dos anos 1960 eram bem definidos e divididos patriarcalmente no Brasil. Em uma sociedade onde o governo não podia ser contrariado, assim como os pais de família, “os castigos físicos ainda eram tidos como estratégias educativas, sexo era tabu" (MACIEL, 2009, p. 2) e as mulheres eram ensinadas a serem donas de casa, mães e obedientes aos seus maridos. Nesse contexto, tomou força não somente no Brasil, mas em quase toda a América Latina, a segunda onda do feminismo nos anos de 1970 com o objetivo de combater o autoritarismo dos governos vigentes (COSTA, 2005), sendo um movimento mais liberal que o anterior na década de 60 (PAXTON; HUGHES, 2016).

As minorias sociais, grupo em que as mulheres se encontravam, e, de certa maneira, ainda se encontram, estão cada vez mais inseridas no contexto do trabalho e a pressão para a contratação desses grupos tem sido cada vez maior, mas também tem sofrido resistência à medida que ganham força (SCOTT, 2005), algo semelhante ao que acontece no meio político, onde a pouca porcentagem de mulheres presentes nas instituições políticas ainda não é tida como um problema para muitas pessoas, dificultando, assim, a valorização de medidas que buscam a igualdade de gênero (RANGEL, 2010).

Quando o movimento ganhou força e as mulheres foram às ruas em busca de igualdade, elas negavam o comportamento e o lugar historicamente atribuído a elas (SARTI, 2004) de serem apenas mães e donas de casa. Para Scott (2005, p. 15) a igualdade "não é a ausência ou a eliminação da diferença, mas sim o reconhecimento da diferença e a decisão de ignorá-la ou levá-la em consideração". Reivindicar igualdade é reconhecer a diferença e lutar para que ela seja não seja um impedimento para o gozo e alcance de direitos iguais.

A presença feminina na política começa a ser mais visível no final do séc. XX, principalmente, em cargos mais elevados (ARAÚJO, 2001) como mostram Dias e Sampaio (2011), ao apresentarem dados que mostram que o número de mulheres que se candidataram ao cargo de deputada estadual subiu de 571, em 1994, para 3274 em 2010, assim como o número de candidatas ao Senado que foi de 17 para 36 no mesmo período. Mas questões culturais ainda exercem influência sobre a pouca inserção e representação da mulher na política, visto que, mesmo que conquistas sejam alcançadas, a baixa visibilidade da mulher em alguns momentos perante a sociedade ainda compromete a realização plena de direitos políticos e de cidadania (DIAS; SAMPAIO, 2011) que, por sua vez, só podem acontecer quando há um grau de autonomia e reconhecimento do indivíduo pela sociedade (ARAÚJO, 2011).

A importância de considerar que ainda existem bloqueios à participação feminina na política se dá pelo fato de que a presença de mulheres no meio político é importante para a diversificação dos discursos, em função de a mulher construir uma identidade e partir de uma realidade diferente da masculina (LIMA, 2010). Dentro deste contexto estão questões como o direcionamento de dinheiro público, políticas públicas e até mesmo a qualidade das decisões políticas são influenciadas positivamente pela diversidade de gênero dentro de uma instituição pública (PAXTON; HUGHES, 2016).

Nesse sentido, os partidos políticos têm uma parcela de responsabilidade quando se trata da maior representação da mulher na política. A inserção das mulheres nos partidos políticos pode representar apenas 
uma forma de cumprir a "igualdade social", não significa que assim elas consigam consolidar suas propostas. Para que esta representação aconteça, é necessário que sejam garantidos meios e espaços para que as mulheres se articulem e se organizem em torno de assuntos que são de interesse comum (DIAS; SAMPAIO, 2011).

Criar condições justas para competir com os homens na política é um desafio que consiste quase em mudar o conceito de política da população e tentar descontruir gradativamente a denominação de papeis sociais, econômicos e políticos para homens e mulheres (PAXTON; HUGHES, 2016). Dessa forma "a competição partidária mais diversificada, combinada com o surgimento de novos partidos, tende a proporcionar mais oportunidades de ingresso para as mulheres na esfera política” (ARAÚJO, 2005, p. 5).

A busca pela representação política vai além de como as mulheres são representadas. A importância atual é saber quem as representa (ARAÚJO, 2001). Ou seja, as mulheres procuram estarem presentes nas decisões e serem agentes da sua própria representação.

\section{PROCEDIMENTOS METODOLÓGICOS}

O presente estudo é de natureza qualitativa, amparou-se em uma perspectiva interpretativa. Os dados foram coletados por meio da realização de entrevistas semiestruturadas, orientadas por um roteiro de entrevista. $\mathrm{O}$ roteiro de entrevista se orientou pelos seguintes pressupostos: como o(a) entrevistado(a) ingressou na vida política, sua vivência neste meio, a sua opinião sobre a inserção de mulheres na política e sobre a cota específica de gênero, a visão sobre o posicionamento dos partidos acerca das dificuldades enfrentadas pelas mulheres e sobre a cultura patriarcal na sociedade. Para as vereadoras mulheres, foram acrescentadas questões sobre dificuldades, preconceito e o relacionamento com outros vereadores. Cinco sujeitos participaram da entrevista, uma vereadora, uma ex-vereadora, denominadas nesta pesquisa de E1 e E2, e três vereadores, nomeados como E3, E4 e E5, de uma cidade do Sul de Minas Gerais. As entrevistas foram gravadas em áudio e transcritas para a análise. O tempo de duração de cada entrevista variou entre 30 e 50 minutos. A escolha deste método ocorreu pelo fato de as entrevistas semiestruturadas serem de caráter simples e de fácil entendimento por parte dos entrevistados (MANZINI, 2003).

A escolha do local da pesquisa, a câmara de vereadores de uma cidade do sul de Minas Gerais, se deu em função do município deter de um histórico de baixa eleição de mulheres: entre 1996 e 2012, exceto pelo ano de 2008 em que foram 2 mulheres, somente 1 mulher foi eleita como vereadora, enquanto o número de candidatas oscilou entre 37 e 60 . Buscou-se entrevistar a atual vereadora e ex-vereadoras, porém somente uma ex-vereadora esteve acessível.

A vereadora E1 tem 44 anos e está em seu segundo mandato. E2 foi vereadora de 2006 a 2010. O vereador E3 tem 40 anos e está no seu segundo mandato. E4 tem 56 anos e está no primeiro mandato. Por fim, E5 tem 56 anos e está no terceiro mandato, sendo o primeiro 1996-2000 e o segundo 2000-2004. Esses dados sobre os mandatos dos vereadores foram extraídos do site da Câmara de Vereadores da cidade.

O método de análise de dados utilizado foi a análise de conteúdo. De acordo com Godoy (1995), esta técnica metodológica proposta por Laurence Bardin pode ser utilizada em inúmeros tipos de discursos e formas de comunicação. Acrescenta que nesta análise o pesquisador precisa entender o sentido da comunicação, portando-se como um receptor normal, mas necessita também desviar o olhar de modo a obter outra mensagem, outra significação.

Minayo (2000) explica que a análise de conteúdo relaciona as estruturas semânticas, aquilo que foi expresso nos documentos analisados, com os significados dos fragmentos, as quais a autora denomina de es- 
truturas sociológicas. É uma busca de articulação entre "[...] a superfície dos textos descrita e analisada com os fatores que determinam suas características: variáveis psicossociais, contexto cultural, contexto e processo de produção da mensagem" (MINAYO, 2000, p. 203).

Dentre as diversas formas de se analisar o conteúdo, optou-se pela análise de conteúdo temática, na qual, a partir da leitura das entrevistas, emergiram núcleos de sentido comuns e criaram-se categorias temáticas de análise. As categorias foram: A percepção dos entrevistados sobre a mulher na política e o exercício da legislatura na câmara de vereadores, criadas a posteriori.

\section{APRESENTAÇÃO E DISCUSSÃO DOS RESULTADOS}

\subsection{A Percepção Dos Entrevistados Sobre a Mulher Na Política}

Atualmente, a cidade do Sul de Minas Gerais ao qual se refere este estudo possui 15 vereadores, eleitos em 2012, sendo apenas uma mulher. Junto a ela, no mandato passado, a cidade contou com mais uma vereadora, que não foi reeleita.

As opiniões das entrevistadas quanto à maior participação da mulher na política são muito parecidas, assim como as dificuldades enfrentadas por elas. A princípio, elas se limitaram a comentar dificuldades do cargo de vereadora sem tratarem do fato de serem mulheres, mas, ao longo da entrevista, perceberam-se alguns traços de discriminação sofrida por elas. Isso é perceptível nos relatos, mas elas não reconhecem que sofreram discriminação, de maneira direta.

A partir das falas das entrevistadas percebeu-se que o próprio partido político as coloca nas candidaturas para cumprir a legislação, mas não espera que elas sejam efetivamente eleitas, conforme relato a seguir.

Eles garantem 30\% das legendas, ou seja, das candidaturas. Lançam 30\% de candidatas nas eleições, porém teria que ser $30 \%$ das cadeiras, assim como na África, que são eleitas $30 \%$ de mulheres (...) Eu já tive propostas para candidatar para deputada estadual só para preencher a legenda, e eu desisti (E1).

Percebe-se, pelo relato, que ocorre uma preocupação por parte dos partidos políticos em ter mulheres nas legendas, mas pode ser que isso seja apenas uma obrigação para cumprir a lei e não efetivamente uma preocupação para acabar ou diminuir a desigualdade vivenciada por mulheres na política, situação essa que foi um dos motivos para uma mudança na lei de cotas, como ressaltado por Rangel (2010) e Dias e Sampaio (2011). Os entrevistados afirmam que os partidos políticos dizem dar muito espaço às mulheres, mas é preciso questionar que isso ocorre não porque eles acham que elas precisam ter representantes e que essa desigualdade precisa ser superada, mas porque os partidos têm que cumprir a lei. Outro relato que reforça esse argumento e a visão de E1, é a opinião de E3, quando se trata de igualdade entre homens e mulheres na política:

Eu não acho necessária [a igualdade], porque hoje a lei já garante pelo menos 30\% das vagas dos candidatos para as mulheres e nós não estamos conseguindo atingir nem 10\%. Então para que igualdade de $50 \%$ se nós não atingimos nem $10 \%$ ? (E3).

Como E1 relatou que já foi convidada a se candidatar apenas para cumprir legenda, E3 confirma que a preocupação de alguns partidos políticos quanto à política de cotas estaria mais voltada para o cumprimento da lei que obriga que tenham mulheres nas legendas eleitorais. Ter mulheres na legenda deveria significar que a representação delas está aumentando e é isso que elas buscam e que os partidos deveriam incentivar mais. 
Certamente, se não houvesse a política de cotas, as mulheres teriam menores chances de se inserir na política, assim como acontecia antes dos anos 1990, quando não havia essa política (BRASIL, 2014). Algo que chama a atenção é que um dos vereadores defende a igualdade entre homens e mulheres na política, mas culpa as mulheres por isso não acontecer.

\begin{abstract}
A lei já é bastante favorável à participação das mulheres na política. O que está acontecendo é um desinteresse na vocação das mulheres para a política. E isso é uma pena porque as mulheres têm demonstrado maior seriedade, maior sensibilidade com a coisa pública. Devemos sempre lembrar de resgatar as mulheres para o meio político (E3).
\end{abstract}

Contrapondo-se ao relato de E3, é preciso destacar que a lei é favorável atualmente e foi criada para estimular e aumentar a participação da mulher na política, que antes era menor, mas existem desigualdades históricas que o relato de E3 faz parecer que já acabaram. Outro ponto que chama atenção é quando o vereador fala sobre o desinteresse das mulheres na política. Apesar de os valores culturais terem mudado bastante nas últimas décadas, como disse Miguel (2001), ainda há homens e mulheres que são socializados a partir de uma perspectiva que considera mais comum que os cargos políticos sejam ocupados por homens, e talvez esse seja o motivo do desinteresse de mulheres pela política. Outra questão que merece destaque no relato é o trecho "devemos sempre lembrar de resgatar as mulheres para o meio político", pois denota a ideia de que há espaços ou lugares específicos para homens e para mulheres, no caso, o da mulher, tradicionalmente, não seria o político.

No discurso dos entrevistados, a visão de falta de interesse por parte das mulheres foi comum. Mas se não houver políticas públicas para inserirem as mulheres na política, como sugeriram Dias e Sampaio (2011), as mulheres terão poucas chances de estar na política e isso implica na falta de chance de conseguir lutar pela igualdade na política.

Culpar as mulheres por não estarem na política não é uma opinião apenas do vereador E3, E1 também acha que as mulheres não estão em maior número porque "mulher não vota em mulher", "mulheres são desunidas", "mulheres não confiam nelas mesmas para exercer o poder". Isso mostra que há uma falta de reflexão em relação aos papéis construídos socialmente para homens e mulheres. Como disse Miguel (2001), tradicionalmente, as mulheres e os homens foram ensinados que o papel da mulher estaria bastante ligado ao contexto privado, marcados por elementos como a maternidade e a obrigação pelos cuidados do lar, o que dificulta maior identificação com o espaço público, em especial, o da política. Os relatos reforçam uma visão tradicionalista orientada pela construção social de estereótipos que influenciam as pessoas a, equivocadamente, definirem posições e papéis sociais para homens e para mulheres, mas que, há várias décadas vem sendo questionados como feito por Lima (2010) e Rangel (2010). Por conta disso, mulheres têm conseguido, cada vez mais, ocupar espaços e posições historicamente ocupados por homens, apesar de ainda lutarem contra as desigualdades ainda existentes.

É interessante ressaltar a contradição no relato de E4, pois afirma que o machismo vem sendo superado, mas ele mesmo culpa as mulheres por não estarem na política.

Os motivos são vastos, desde a falta de preparo, interesse, timidez da mulher, até o machismo, muitas das vezes também impera para que a mulher não alcance os objetivos, fatores que ao longo do tempo vem sendo superados (E4).

E4 parece observar o que acontece na própria cidade onde ele exerce a função de vereador. Se esse machismo estivesse, de fato, sendo superado, como ele diz, a cidade não teria apenas uma vereadora nesse 
mandato, quando eram duas no mandato passado e em um universo de 15 eleitos. Os entrevistados também possuem a mesma visão sobre isso. Se as mulheres se unirem e votarem em mulheres, esse "problema" de pouca representação delas na política pode acabar, conforme relato de E1.

\begin{abstract}
Sessenta por cento do eleitorado (da cidade) é mulher. Se a gente quisesse, a gente colocava só mulher nessa câmara. Porque não consegue? Porque é aquele velho ditado: mulher não vota em mulher. Enquanto nós não mudarmos isso, nós não vamos conseguir e vamos continuar falando aquilo que eu falei antes "é um mundo machista", mas é porque eu deixo ser. Se nós nos unirmos mais, mas a nossa criação, nossos antepassados... é uma disputa, uma coisa que está arraigada mesmo em nós. Parece que as mulheres pensam "eu não vou estar lá mesmo, porque eu tenho que votar nela?". É uma disputa mesmo. Os homens são mais unidos. [...] Ficar esperando o governo que é predominantemente feito por homens fazer alguma coisa por nós, não vai adiantar. Inclusive estou tendo uma ideia, acho que vou formar um partido só de mulheres. Imagina, ficaria muito mais fácil (E1).
\end{abstract}

Esse relato evidencia a ausência de um posicionamento reflexivo e consciente sobre o papel da política de cotas, assim como sobre os papéis sociais esperados para homens e mulheres baseados em estereótipos construídos socialmente. Na visão de E1 acabar com a desigualdade entre homens e mulheres na política perpassa pela ideia de união entre as mulheres, mas se elas não tiverem oportunidade de estarem na política, principalmente, por meio de políticas públicas de promoção da igualdade de gênero, fica mais difícil que a mudança de pensamento e o rompimento dos laços de uma sociedade machista e patriarcal aconteçam.

Inclusive, E1 acredita que poderia ter mais companheiras ao seu lado na câmara dos vereadores da cidade se as mulheres votassem em mulheres. Ela menciona que essa união pode chegar e até se transformar em um partido só de mulheres. Mas, um partido só para mulheres poderia significar a separação entre mulheres e homens na disputa política o que poderia representar um reforço ao preconceito. A saída não é separar as mulheres dos homens, pelo contrário, a busca pela igualdade é a busca por unir homens e mulheres sem que as mulheres sofram preconceito por estarem onde estão, ou seja, minorias colocadas na política apenas para cumprimento de uma lei.

\title{
5.2. O Exercício Da Legislatura Na Câmara De Vereadores
}

Os relatos sobre a convivência entre os vereadores e a vereadora, a princípio, demonstram uma boa relação entre eles, mas alguns elementos em seus relatos demonstram que essa relação talvez não seja tão boa. No mandato passado (2006-2010) havia mais uma vereadora, E2 ao lado de E1, e o relato desta, em relação a isso, entra em contradição com a noção de boa convivência.

\footnotetext{
No primeiro mandato, tinha mais uma. Eu me sentia melhor, porque nós mulheres somos mais sensíveis, mais intuitivas. Os homens são práticos, racionais. Então, essa dificuldade eu sinto muito. Consigo ter um outro olhar, com a mesma resposta que eles têm, então eu procurava o olhar dela como quem diz "estou entendendo o que você quer falar" (E1).
}

Mesmo com a boa relação que eles afirmam ter hoje e que tinham também no mandato passado entre vereadores e vereadoras, era mais fácil e mais confortável para E1 ter E2 ao seu lado na câmara. E1, porém, reforça a estereotipação que existe sobre a racionalidade masculina e sentimentalismo feminino. Quando ela diz que conseguia ter "um outro olhar" com E2, ela, sem querer, mostra que era mais confortável ter outra mulher ao seu lado e que agora ela talvez se sinta mais intimidada sendo sozinha, contrariando o que foi dito pelos vereadores. Ela mesma afirma que a "disputa política existe", mas sofre preconceito por ser mulher. Contudo, 
se ela não sofresse preconceito, ter ou não outra mulher ao seu lado na Câmara seria algo indiferente, o que não é o caso. E2 também afirma que se sentia confortável quando estava exercendo sua candidatura, mas, assim como E1, entra um pouco em contradição mais adiante na entrevista:

Quando estive como vereadora, éramos duas, mas acredito que poderia ter mais, pois os homens não acreditam muito em nós mulheres, no meu caso, não sei falar algo que não posso cumprir, e na política não é bem assim, algumas vezes tive problemas em votação de alguns projetos, pois não comungo benefício próprio (E2).

Assim como E1, E2 leva sempre a questão de desconforto na política e preconceito para o discurso que as coisas na política não são fáceis, mas não têm relação com a questão de ela ser mulher. Porém, ela afirma que os homens não acreditam muito nas mulheres, o que entra em desacordo com as respostas dos vereadores e vereadoras. Se ela afirma que os homens não acreditam nas mulheres, então ela talvez tenha sofrido algum tipo de discriminação por ser mulher e estar em um ambiente em que a maioria é homens. Um relato que mostra isso é o de E5, ao achar que as mulheres precisam parar de querer se igualar aos homens e distinguir homens e mulheres através de estereótipos:

\begin{abstract}
Acho que em muitos setores a igualdade feminina levou-se em conta as mulheres se igualarem aos homens, o que não é salutar, cada um deles têm suas características e em muitos setores a mulher é muito melhor que o homem. Assim acho que não tem que se mirar no homem e sim em desenvolver sua capacidade de raciocínio, sua capacidade de lidar com vários assuntos ao mesmo tempo, fato raro nos homens e principalmente na sua forma de visão das coisas, que são peculiares. Não devem se mirar nos homens e sim desenvolver suas inúmeras capacidades para mostrar que em muitos setores elas são muito melhores (E5).
\end{abstract}

O discurso do vereador E5 chega a demonstrar um desconhecimento sobre a luta pela busca pela igualdade entre homens e mulheres. Esse conceito de igualdade que E5 comenta, demonstra o preconceito dele próprio sobre a igualdade entre homens e mulheres através do desconhecimento sobre o que as mulheres buscam. Talvez, ele não encare isso como preconceito, mas seu discurso é pautado no princípio que os homens são os mais fortes e mais capazes. As mulheres não buscam serem homens, eles buscam serem reconhecidas da mesma forma que eles quando ambos exercem as mesmas funções.

Por mais que todos afirmem ir contra o pensamento machista e até citar algumas vezes que é isso que influencia na falta de mais mulheres na política, culpar as mulheres por não estarem na política, até algumas vezes afirmando que elas não querem isso, mostra uma contradição e uma ausência de reflexão e conhecimento sobre as desigualdades sociais e históricas vivenciadas por mulheres.

Se o discurso dos vereadores for levado em consideração para resolver o problema da desigualdade entre homens e mulheres na política, não se faz necessária nem mesmo a política de cotas, na sua forma de reserva de assentos parlamentares para mulheres, pois se o eleitorado de mulheres supera o dos homens, a solução é as mulheres se unirem, votarem nelas mesmas e o governo não precisa inserir políticas públicas para ajudar nisso. Desconsiderando as opiniões dos entrevistados, sem a política de cotas, ou qualquer outra que possa incentivar a inserção de mulheres na política, seria mais difícil a inserção de mulheres nesse meio culturalmente ocupado por homens e lutar pela igualdade. 
O presente trabalho objetivou discutir a inserção e vivência de mulheres na política, no legislativo de uma cidade do sul de Minas Gerais, na perspectiva dos vereadores e vereadoras. Pelos relatos dos entrevistados, percebeu-se a maneira homogênea como os vereadores comentam sobre a ausência de mulheres na política, isso demonstra certa ausência de reflexão sobre as desigualdades sociais e históricas vivenciadas por mulheres. Alguns entrevistados justificam a baixa presença de mulheres na política como culpa delas mesmas, por não se interessarem por política. Mas, eles não chegam a questionar esse desinteresse, nem a pensar que essa falta de interesse vem de uma naturalização baseada na ideia de que esses cargos tradicionalmente eram mais associados aos homens, ou seja, o espaço público e da política, historicamente, foi construído como o espaço deles. Mas, é preciso destacar que os papéis sociais construídos para homens e mulheres vêm se modificando, ao longo dos anos, por isso, as mulheres estão se inserindo mais na política, mesmo que ainda enfrentando desigualdades e dificuldades.

Mesmo já tendo conquistado seu espaço em muitos outros campos de trabalho, as mulheres ainda sofrem preconceito e a desigualdade de gênero. A última eleição, no ano de 2014, mostrou um pequeno aumento da eleição de deputadas e senadoras, mas é muito inferior à quantidade de homens existentes no congresso. Na cidade do sul de Minas Gerais, foco deste estudo, a última eleição municipal, em 2012, elegeu apenas uma vereadora e até 2011 eram duas. Mas a inserção das mulheres na política não garante, necessariamente, a igualdade de participação entre homens e mulheres na câmara de vereadores, como mostraram os relatos das vereadoras entrevistadas, indicando que a representação ainda é permeada pela construção social acerca do papel da mulher e sua esterotipação como um indivíduo menos racional.

A política de cotas pode ser considerada um avanço, mas não resolve todas as dificuldades. Ajuda no sentido de haver mulheres inseridas na política que podem contribuir para mudar o pensamento das outras mulheres e homens em relação aos papéis sociais que elas e eles ainda estão acostumados a reproduzir. As cotas incentivam a participação, mesmo que ainda não seja um objetivo principal dos partidos políticos, visto que os mesmos estão pouco preocupados em acabar com a desigualdade e aumentar o número de mulheres na política pela importância que isso teria.

O Brasil ainda precisa melhorar na questão da desigualdade entre homens e mulheres na política. Uma ação para que a desigualdade comece a diminuir seria a permanência das cotas juntamente com a constante luta acerca da reserva de assentos no legislativo, além da adoção de medidas que busquem levar para diversas instituições o debate sobre a questão da construção social do gênero, de forma a tentar conscientizar toda a população sobre as desigualdades que ainda persistem.

\section{REFERÊNCIAS BIBLIOGRÁFICAS}

ARAÚJO, C. 2001. As cotas por sexo na competição legislativa: o caso brasileiro em comparação com as experiências internacionais. Dados, Rio de Janeiro, v. 44, n. 1, p. 155-194.

ARAÚJO, C. 2005. Partidos políticos e gênero: mediações nas rotas e ingresso das mulheres na representação política. Revista Sociologia Política, Curitiba, n. 24, p. 193-215.

ARAÚJO, C. 2011. As mulheres e o poder político - desafios para a democracia nas próximas décadas. In: BARSTED, L. L.; PITANGUY, J. O progresso das mulheres no Brasil 2003 - 2010. Rio de Janeiro: Cepia. BRASIL. 1997. Lei no 9.504, de 30 de setembro de 1997. Estabelece normas para as eleições. Diário Oficial [da] República Federativa do Brasil, Brasília, 30 de setembro de 1997. Disponível em: [ http://www.planal- 
to.gov.br/ccivil_03/leis/L9504.htm]. [23 jun. 2016]

BRASIL. 2009. Lei $\mathrm{n}^{\mathrm{o}}$ 12.034, de 29 de setembro de 2009. Altera as Leis nos 9.096, de 19 de setembro de 1995 - Lei dos Partidos Políticos, 9.504, de 30 de setembro de 1997, que estabelece normas para as eleições, e 4.737, de 15 de julho de 1965 - Código Eleitoral. Diário Oficial [da] República Federativa do Brasil, Brasília, 29 de setembro de 2009. Disponível em: [http://www.planalto.gov.br/ccivil_03/_ato2007-2010/2009/ lei/112034.htm]. [23 jun. 2016]

BRASIL. (2012). Mulheres na política. Disponível em: [http://www.brasil.gov.br/cidadania-e-justica/2012/02/mulheres-na-politica]. [15 out. 2015].

BRASIL. (2014). Mais mulheres na política: mulher, tome partido! Disponível em: [http://www12.senado. gov.br/institucional/procuradoria/pesquisa/livreto-mais-mulheres-na-politica]. [28 jan. 2016].

COSTA, A. A. A. 2005. O movimento feminista no Brasil: dinâmicas de uma intervenção política. Gênero, Niterói, v. 5, n. 2, p. 9-35, jan./jul.

DIAS, J. SAMPAIO, V. G. 2011. A inserção política da mulher no Brasil: uma retrospectiva histórica. Estudos Eleitorais, Brasília, v. 6, n. 3, p. 55-92, set./dez.

GODOY, A. S. 1995. Pesquisa qualitativa: tipos fundamentais. Revista de Administração de Empresas, São Paulo, v. 35, n. 3, p. 20-29, mai.jun.

GROSSI, M. P. MIGUEL, S. M. 2001. Transformando a diferença: mulheres na política. Estudos Feministas, Florianópolis, vol. 9, n. 1, p. 167-206, jul./dez.

KROOK, M. L. 2010. Quotas for women in politics: gender and candidate selection reform worldwide. New York: Oxford University Press.

LIMA, F. F. P. A. 2010. Entre o diálogo e a (re)significação do sentido: um olhar sobre a identidade da mulher política. Bakhtiniana, São Paulo, v. 1, n. 3, p. 99-112, jan./jun.

MACIEL, M. E. 2009. A (r)evolução dos costumes: nada mudou, tudo mudou. Organon, Porto Alegre, v. 23, n. 47, p. 65-71, jul./dez.

MANZINI, E. J. 2003. Considerações sobre a elaboração de roteiro para entrevista semi-estruturada. In: MARQUEZINE, M. C. ALMEIDA, M. A. OMOTE, S. Colóquios sobre pesquisa em educação especial. Londrina: Eduel.

MARTINS, G. A.; THEÓPHILO, C. R. 2009. Metodologia da investigação científica para ciências sociais aplicadas. 2.ed. São Paulo: Editora Atlas S.A.

MIGUEL, L. F. 2001. Políticas de interesses, política do desvelo: representação e singularidade feminina. Estudos Feministas, Florianópolis, v. 9, n.1, p. 253-267, jul./ago.

MIGUEL, L. F.; BIROLI, F. 2010. Práticas de gênero e carreiras políticas: vertentes explicativas. Estudos Feministas, Florianópolis, v. 18, n. 3, p. 653-679, set./dez.

MINAYO, M. C. S. 2000. O desafio do conhecimento: pesquisa qualitativa em saúde. 7. ed. São Paulo: Hucitec.

MORAES, R. 1999. Análise de Conteúdo. Revista Educação, Porto Alegre, v. 22, n. 37, p. 7-32.

PAXTON, P. HUGHES, M. M. 2016. Women, politics, and power: a global perspective. 3. ed. Washington: CQ Press.

PHILliPS, A. 2001. De uma política de ideias a uma política de presença? Estudos Feministas, Florianópolis, ano 9, p. 268-290, jul./dez.

RANGEL, P. 2010. Participação feminina na política institucional: análise do sistema eleitoral brasileiro e sugestões de mudança. In: . Relatório anual do Observatório Brasil de Igualdade de Gênero 
2009/2010. Brasília: Secretaria Especial de Políticas para as Mulheres.

ROCHA, C. S. M. (2010). Direitos da mulher: uma história de dominação e luta. Disponível em: [http:// sociologiacienciaevida.uol.com.br/ESSO/Edicoes/22/artigo127779-1.asp]. [11 nov. 2015]

SACCHET, T. 2011. Partidos políticos e (sub)representação feminina: um estudo sobre recrutamento legislativo e financiamento de campanhas. In: PAIVA, D. (Org.). Mulheres, política e poder. Goiânia: Cânone. SARTI, C. A. 2004. O feminismo brasileiro desde os anos 1970: revisitando uma trajetória. Estudos Feministas, Florianópolis, vol. 12, n. 2, p. 35-50, mai./ago.

SCOTT, J. W. 2005. O enigma da igualdade. Estudos Feministas, Florianópolis, v. 13, n. 1, p. 11-30, jan./abr. VAZ, G. A. (2008). A participação da mulher na política brasileira: a lei de cotas. Disponível em: [http:// bd.camara.gov.br/bd/bitstream/handle/bdcamara/5813/participacao_mulher_vaz.pdf?sequence=4]. [09 set. 2015]

YOUNG, I. M. 2006. Representação política, identidade e minorias. Lua Nova, São Paulo, v. 67, p. 139190. 